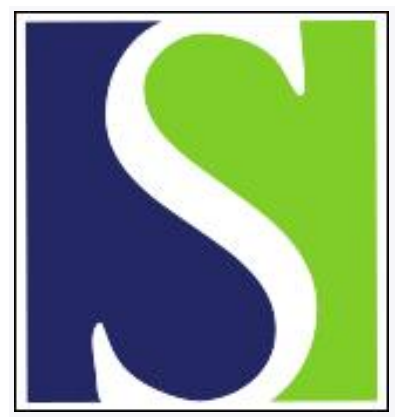

Scand J Work Environ Health 2019;45(6):610-621

https://doi.org/10.5271/sjweh.3842

Published online: 11 Aug 2019, Issue date: 01 Nov 2019

Physical capability in midlife and risk of disability pension and long-term sickness absence: prospective cohort study with register follow-up

by Sundstrup E, Hansen ÅM, Mortensen EL, Poulsen OM, Clausen T, Rugulies R, Møller A, Andersen LL

The results of this study show that low levels across a range of physical capabilities are - in a dose-response fashion - strongly and negatively associated with disability pension and long-term sickness absence. Population attributable risk for disability pension from low physical capability was $42 \%$. Political initiatives to ensure good physical capabilities of older workers should, therefore, be prioritized.

Affiliation: National Research Centre for the Working Environment,Lersø Parkallé 105, 2100 Copenhagen, Denmark. esu@nrcwe.dk

Refers to the following texts of the Journal: $2000 ; 26(2): 161-168$

2013;39(6):599-608 2017;43(1):15-23 2017;43(1):24-33

2017;43(2):146-154 2017;43(5):415-425

Key terms: aerobic fitness; disability pension; exercise; labor market; long-term sickness absence; lung capacity; maximal oxygen uptake; midlife; muscle strength; older worker; physical capability; physical capacity; prospective cohort study; register follow-up

This article in PubMed: www.ncbi.nlm.nih.gov/pubmed/31411336

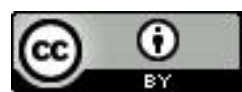




\title{
Physical capability in midlife and risk of disability pension and long-term sickness absence: prospective cohort study with register follow-up
}

\author{
by Emil Sundstrup, PhD, ${ }^{1}$ Ase Marie Hansen, PhD, ${ }^{1,2}$ Erik Lykke Mortensen, MSc, ${ }^{2,3}$ Otto Melchior Poulsen, Dr Vet Sci, ${ }^{1}$ \\ Thomas Clausen, PhD, ${ }^{1}$ Reiner Rugulies, PhD, ${ }^{1,2,4}$ Anne Møller, PhD, ${ }^{5,6}$ Lars Louis Andersen, PhD 1,7
}

\begin{abstract}
Sundstrup E, Hansen ÅM, Mortensen EL; Poulsen OM, Clausen T, Rugulies R, Møller A, Andersen LL. Physical capability in midlife and risk of disability pension and long-term sickness absence: prospective cohort study with register follow-up. Scand J Work Environ Health. 2019;45(6):610-621. doi:10.5271/sjweh.3842
\end{abstract}

\begin{abstract}
Objective The aim of this study was to determine the association of physical capability with health-related labor market outcomes among older workers.

Methods The prospective risk of disability pension and long-term sickness absence (LTSA) of $\geq 6$ weeks was estimated from physical capability on 5076 older workers (age 49-63 years) from the Copenhagen Aging and Midlife Biobank (CAMB). Physical capability was objectively measured through nine different tests (jump performance, postural balance, chair-rise, explosive muscle strength, maximal strength of the hand, back and abdominal muscles, lung capacity, and aerobic fitness) and linked to a high-quality register on social transfer payments among all Danish residents. Cox-regression analyses estimated the association of physical capability with risk of disability pension and LTSA.
\end{abstract}

Results For all measures, low physical capability [ $\geq 1$ standard deviation (SD) below the mean for each gender] was associated with increased risk of disability pension and/or LTSA, whereas high physical capability ( $\geq 1$ SD above the mean for each gender) was not. A capability-response association was observed between the number of tests with low capability and disability pension and LTSA $(\mathrm{P}<0.0001)$ - with the risk-estimate for disability pension being 8.52 (95\% confidence interval 3.98-18.25) when low capability was present in $\geq 5$ physical tests. Population attributable risks analyses indicate that $42 \%$ of the disability pension cases were attributable to low physical capability whereas this was the case for $12 \%$ of the LTSA cases.

Conclusions Using objective measures of predictors and outcomes, our study shows that low physical capability in midlife was associated with increased risk of disability pension and LTSA. The results indicate that increasing physical capability to an average level among older workers with low capability could potentially contribute to preventing $>40 \%$ of premature exits from the labor market.

Key terms aerobic fitness; exercise; labor market; lung capacity; maximal oxygen uptake; muscle strength; older worker; physical capacity.

Due to the demographic changes observed during the last decades, keeping older workers in the labor market is a political priority. However, this is not without challenges considering the age-associated decline in health (1-3). This encompasses a decline in physical capacity that sets in around the age of 30 years (2) and a decline in cognitive ability that becomes apparent around the age of 50 after which it accelerates (3). For example, muscle strength decreases by an average of $1-2 \%$ per year from the age of 30 (2). Consequently, workers aged $50-60$ years of age will on average have lost over a third of their muscle strength. Importantly, also the number of coexisting health problems increases with age (4). Even though physical work demands will likely show a

1 National Research Centre for the Working Environment, Copenhagen, Denmark.

2 Department of Public Health, University of Copenhagen, Copenhagen, Denmark.

3 Center for Healthy Aging, University of Copenhagen, Copenhagen, Denmark.

4 Department of Psychology, University of Copenhagen, Copenhagen, Denmark.

5 Department of Occupational Medicine, Holbæk Hospital, Holbæk, Denmark.

6 Research Unit for General Practice and Section of General Practice, Department of Public Health, University of Copenhagen, Copenhagen, Denmark.

7 Department of Health Science and Technology, Aalborg University, Aalborg, Denmark.

Correspondence to: Emil Sundstrup, National Research Centre for the Working Environment,Lersø Parkallé 105, 2100 Copenhagen, Denmark. [E-mail: esu@nrcwe.dk] 
small decrease in many industries due to implementation of new technology $(5,6)$, the age-associated decline in physical capability could lead to a significant proportion of older workers lacking the resources to cope with the physical demands at work (7). This can lead to reduced work ability, poor health, and challenging labor market attachment at an older age.

Physical capability measured by easily administrable tests such as grip strength and walking speed has been proposed as candidate biomarkers of the aging process and indicators of current and future health $(8,9)$. Specifically, low physical capabilities could reflect both diagnosed and undiagnosed disease and aging processes and have been associated with higher rates of mortality in the older population $(8,10)$. However, to capture individuals at earlier stages of the disablement process there is a need to investigate the development and consequence of functional decline and limitations prior to older age $(11,12)$. Elucidating the association of physical capability in midlife with health-related labor market endpoints - eg, long-term sickness absence (LTSA) and disability pension - could help to develop screening tools to identify workers at risk of premature exit from the labor market. Identifying individuals who are more vulnerable to premature exit may help to target future preventive interventions and slow down or postpone the onset of early aging processes in midlife (11).

Previous studies employing both self-rated and objectively measured physical capability have observed an association between low physical capability and poor health (13). Borch-Supan et al (14) observed a significant deterioration of self-assessed health among older participants from the SHARE study who just started to receive disability benefits. However, this deterioration was less pronounced when health was obtained more objectively by hand-grip strength, which indicates justification bias in self-assessed health (14). This is in agreement with Kalwij et al (15) emphasizing the need for objective health indicators when analyzing the association between health status and labor market participation. To our knowledge, only one study has previously examined the association between objectively measured physical capability and labor market participation. That study, by Stafford et al (16), found that better physical capability (ie, grip strength, chair-rise time, one-legged balance test) was associated with a greater likelihood of participating in bridge or voluntary employment after retirement from main occupation (self-reported). However, they found no association with a performance-based physical capability score and retiring for negative reasons (16).

The aim was to determine the association of nine objective measures of physical capability in midlife with register-based disability pension and LTSA among participants from the Copenhagen Aging and Midlife Biobank (CAMB) cohort. It was hypothesized that low physical capability $[\geq 1$ standard deviation (SD) below the mean for each gender] would increase the risk for future disability pension and LTSA, whereas high physical capability ( $\geq 1 \mathrm{SD}$ above mean for each gender) would decrease this risk.

\section{Methods}

\section{Study design}

This prospective cohort study merges data on physical capability from CAMB with a national register containing information on sickness absence and disability benefits. The study follow-up period was 4-6 years and the average time of follow-up was 4.62 years. When reporting on the study, the STROBE checklist was followed to ensure transparent and standardized reporting (17). The methods and design have previously been described (18).

\section{Study population}

The CAMB cohort was established from 2009-2011 by inviting 17937 persons (age 49-63 years) from three existing Danish cohorts [the Metropolit Cohort (19), the Danish Longitudinal Study on Work, Unemployment, and Health (20), and the Copenhagen Perinatal Cohort (21)]. In total 7190 (40\%) completed a survey questionnaire and 5575 further participated in a clinical examination $(31 \%)(22)$. The clinical examination consisted of a health examination and different physical capability tests and took place from 2009-2011. The following exclusion criteria were test-specific: dizziness in regard to the standing balance test; disc herniation and extensive hip-, knee-, and ankle-pain in regard to the jump height test; high blood pressure (BP) (ie, systolic BP $>160 \mathrm{mmHg}$ and/or diastolic $\mathrm{BP}>100 \mathrm{mmHg}$ ) in regard to the chair rise test, strength tests for back and abdominal muscles, and the aerobic fitness test. Individuals not affiliated with the labor market at the point of data collection were excluded from the present study. After exclusion, the study population consisted of 5076 workers (age 49-63 years at baseline). Because not all participants performed all the physical capability tests, the exact number of participants for each of the analyses varied.

\section{Physical capability}

Maximal handgrip strength and explosive muscle force [ie, rate of force development (RFD)] were measured with a Jamar dynamometer (model G100, Biometrics Ltd, Newport, UK) wired to a computer's signal conditioning interface (11). The attempt with the highest 
force value $(\mathrm{kg})$ of three to five attempts was used for further analysis. In addition, the test with the highest RFD ( $\mathrm{kg} / \mathrm{s})$ was used for further analysis.

Maximal muscle strength of the abdominal- (trunk flexion) and back muscles (trunk extension) were measured in a standing position in a custom-made dynamometer setting (23). The attempt with the highest force value $(\mathrm{kg})$ of 3-5 attempts was used to determine maximal strength.

Functional lower limb capability was measured as the number of chair-rises performed during a 30 -second sit-to-stand test (24). The test was performed using a chair (height $45 \mathrm{~cm}$ ) with a mechanical contact in the seat, enabling automatic recording of the number of chair-rises completed (25).

Postural balance was assessed by three one-legged balance tests performed for 30 seconds on an instrumented force plate (AMTI OR6, Watertown, MA, USA) (11). The attempt with the lowest sway area of the center of pressure was selected for further analysis. Maximal vertical jump height was assessed during countermovement jumping on the same force plate (26). The attempt with the highest jump height $(\mathrm{cm})$ of 3-5 attempts was used for further analysis.

Aerobic fitness was estimated from a submaximal cycle ergometer test as previously described by Åstrand \& Ryhming (27). Aerobic fitness ( $\mathrm{ml} / \mathrm{kg} / \mathrm{min}$ ) was then calculated as maximal oxygen uptake $(1 / \mathrm{min}) /$ bodyweight $(\mathrm{kg}) \times 1000$.

Lung capacity was assessed by the forced expiratory volume in the first second $\left(\mathrm{FEV}_{1}\right)$ during a spirometry test (28). The attempt with the highest $\mathrm{FEV}_{1}$ (\% of predicted $\mathrm{FEV}_{1}$ ) of 3-5 attempts was used for further analysis.

\section{Physical capability composite score}

A physical capability composite score was created by summing the number of tests with low capability for each participant (ie, $\geq 1$ SD below the mean for each gender). The aerobic fitness test was introduced late within the baseline measurement period and data were therefore obtained from a sub-group consisting of 1313 participants. The analyses with aerobic fitness as predictor were therefore exploratory by nature and not included in the physical capability composite score. Thus, the composite score ranged from $0-8$ and a datadriven categorization to ensure an adequate number of persons in each category was employed to further divide the score into the following 4 categories: (i) " 0 " test with low capability, (ii) " $1-2$ " tests with low capability, (iii) "3-4" tests with low capability, and (iv) " $\geq 5$ " tests with low capability. Because few individuals had 7 and 8 tests with low capacity, the upper limit was set to $\geq 5$.

\section{Outcome variables}

Information on disability pension and LTSA was derived from the Danish Register for Evaluation of Marginalization (DREAM), containing information on all social transfer payments on all Danish residents (29) and linked to the CAMB cohort via the unique Danish personal identification number. In the DREAM register, sickness absence is recorded on a weekly basis when the employer is entitled to reimbursement of the sickness absence pay (30). During the study follow-up, the period during which the employer received no reimbursement changed from 21 days to 30 days of sickness absence (January 2012). Since 30 calendar days represents $>4$ weeks, ie, it goes into the $5^{\text {th }}$ week, and given that sickness absence is recorded on a weekly basis in DREAM, $\geq 6$ consecutive weeks was used as a measure of sickness absence of $>30$ calendar days. To define LTSA consistently throughout the follow-up period, it was therefore defined as $\geq 6$ consecutive weeks in DREAM $(31,32)$.

\section{Covariates}

Age is considered a confounder since physical capacity decreases over time and the number of health problems increases with age thus influencing the likelihood of health-related labor market outcomes such as LTSA and disability pension.

Height and weight are strongly correlated with physical capability (33), and body mass index (BMI) has been associated with poor health and mortality (34). Height and weight of participants were measured by the clinical personnel and BMI was calculated as BMI $(\mathrm{kg} /$ $\mathrm{m}^{2}$ ) $=$ body weight $/(\text { height })^{2}$.

Smoking status is associated with poor health, mortality and physical capability (35). Smoking was evaluated by a question from the CAMB questionnaire: "Do you smoke?" With the response categories: (i) yes, daily; (ii) yes, but not daily; (iii) no, but I have smoked previously; (iv) no, I have never smoked. For the analyses, the response categories i-iii were collapsed into "smoking" while response category iv represented "no smoking".

Education is associated with physical fitness and health and could therefore also be considered a confounder (36). Level of education was categorized into five groups; unskilled, skilled, and short-, medium-, and long-term education (37). For further analyses, a variable was generated corresponding to the educational level, with 1 representing the lowest level of education (ie, unskilled) and 5 representing the highest level of education (ie, long-term education).

Factors within the physical and psychosocial work environment have been associated with both healthrelated labor market outcomes and physical capabil- 
ity $(25,31)$. For instance, higher physical exposures throughout working life have been associated with slightly poorer chair-rise performance in midlife (25). Psychosocial work environment was assessed by seven dimensions from the Copenhagen Psychosocial Questionnaire (38) that was modified to retrospectively cover the participants' entire working life: (i) quantitative demands, (ii) influence/decision authority, (iii) emotional demands, (iv) time pressure, (v) role conflicts, (vi) possibilities for development, and (vii) rewards/ appreciation. Physical work environment was assessed by number of years during working life with (i) mostly sedentary work without physical strain, (ii) mostly standing or walking work without major physical strain, (iii) mostly standing or walking work with some lifting and carrying, (iv) mostly heavy, fast or physically demanding work (31). The data on exposure years in each of the four categories were transformed into a number between 0 and 100 and categorized into low (0-24.99), moderate (25-49.99), high (50-74.99), and very high (75-100) physical work demands.

Poor health is an important determinant of transition into disability pension and sickness absence and musculoskeletal disorders, cardiovascular diseases, depression and anxiety have been shown to predict the risk of these health-related outcomes (39-41). Persons with decreased physical capability are more likely to experience poor health (ie, one or more diseases), which could be the cause of disability pension and LTSA. Further, poor physical capability can be a consequence of several chronic diseases that could also be the main causes of disability pension and LTSA. Thus, chronic diseases could influence both the level of physical capability and the different health-related labor market outcomes. Chronic diseases were assessed by the following question: "Do you have or have you had any of the following diseases?" with the response options "yes, have now", "yes, previously" or "no" to the following diseases: back disease, cancer including leukemia, chronic anxiety or depression, stroke, hypertension, myocardial infarction, and angina pectoris. For each chronic disease, a binary variable was generated: 1 representing that the participant has or had the specific disease, and 2 representing that the participant never had the specific disease.

Previous LTSA is a strong predictor of future LTSA, disability pension, and low physical capability. Previous LTSA (ie, $\geq 6$ consecutive weeks) was assessed from the DREAM register two years prior to the baseline measurements.

\section{Statistical methods}

The Cox proportional hazard model was used to test the associations of each of the nine measures of physical capability and the capability composite score with register-based LTSA and disability pension during the 4-6 year follow-up period (ie, baseline measurements were assessed from 2009-2011 and register follow-up were in 2015). When individuals had an onset of LTSA and disability pension within the follow-up period, the survival times were non-censored and referred to as event times. The analyses were censored for all events of permanent drop-out from the labor market within the follow-up period (ie, early retirement, emigration, and death). The different models in the analyses were adjusted as follows: the minimally adjusted model 1 was adjusted for age and gender; the fully adjusted model 2 was additionally adjusted for education, lifestyle factors (smoking, BMI), physical work environment, psychosocial work environment, chronic diseases (back disease, cancer including leukemia, chronic anxiety or depression, stroke, hypertension, myocardial infarction, and angina pectoris) and previous LTSA. In addition, a sensitivity analysis was performed by additionally adjusting model 2 for self-rated health. Self-rated health was operationalized as a continuous variable ranging from 1 (excellent) to 5 (poor). To test for the existence of capability-response relationships between the number of physical tests with low capability and LTSA and disability pension statistically, trend tests were performed by including the capability composite score as continuous variables in the Cox proportional hazard model. Population attributable risks from low physical capability were calculated for both disability pension and LTSA. This analysis was based on the hazard ratios (HR) and proportions exposed from model 2 in the analysis employing the physical capability composite score (42). Additionally, the interaction for gender was tested for the association between the different physical capacity measures and LTSA. Unless otherwise stated, the estimation method was maximum likelihood and the results are reported as $\mathrm{HR}$ with $95 \%$ confidence intervals (CI). The significance level was set at an alpha level of $\mathrm{P}<0.05$.

\section{Results}

The characteristics of the study population are presented in table 1. Mean age of the study sample was 54.3 (SD 3.8) years, and the proportion of men was $70 \%$ since the Metropolit Cohort included only male participants. During the follow-up period, the following number of outcome events occurred: 970 participants (19.3\%) had at least one episode of LTSA and 85 participants $(1.7 \%)$ were granted a disability pension. The number of censored participants in the analyses was: 538 participants $(10.7 \%)$ due to early retirement; 529 participants $(10.4 \%)$ due to granted state pension; 
Table 1. Baseline characteristics of the study sample. [SD=standard deviation.]

\begin{tabular}{|c|c|c|c|c|c|c|c|c|c|c|c|c|}
\hline & \multicolumn{4}{|c|}{ Study sample } & \multicolumn{4}{|c|}{ Men } & \multicolumn{4}{|c|}{ Women } \\
\hline & $\mathrm{N}$ & $\%$ & Mean & SD & $\mathrm{N}$ & $\%$ & Mean & SD & $\mathrm{N}$ & $\%$ & Mean & SD \\
\hline Age, years & 5076 & & 54.3 & 3.8 & 3537 & & 55.2 & 3.3 & 1539 & & 52.0 & 4.0 \\
\hline \multicolumn{13}{|l|}{ Education } \\
\hline Unskilled manual worker & 366 & 7 & & & 243 & 7 & & & 122 & 8 & & \\
\hline Skilled manual worker & 1869 & 38 & & & 1364 & 39 & & & 506 & 33 & & \\
\hline Short-educated non-manual worker & 509 & 10 & & & 329 & 10 & & & 179 & 12 & & \\
\hline Medium educated non-manual worker & 1330 & 27 & & & 822 & 24 & & & 508 & 33 & & \\
\hline Long-educated non-manual worker & 902 & 18 & & & 697 & 20 & & & 206 & 14 & & \\
\hline \multicolumn{13}{|l|}{ Lifestyle } \\
\hline Body mass index $\left(\mathrm{kg} / \mathrm{m}^{2}\right)$ & 5076 & & 26.0 & 4.1 & 3505 & & 26.4 & 3.7 & 1533 & & 25.1 & 4.6 \\
\hline Smoking (yes and ex-smoker) & 1102 & 22 & & & 746 & 22 & & & 329 & 22 & & \\
\hline Smoking (no) & 3922 & 78 & & & 2720 & 78 & & & 1191 & 78 & & \\
\hline \multicolumn{13}{|l|}{ Physical work environment during working life } \\
\hline Sedentary work & 2618 & 53 & & & 1810 & 53 & & & 809 & 54 & & \\
\hline Moderate physical work & 1072 & 22 & & & 713 & 21 & & & 360 & 24 & & \\
\hline Hard physical work & 827 & 17 & & & 589 & 17 & & & 238 & 16 & & \\
\hline Very hard physical work & 414 & 8 & & & 325 & 9 & & & 89 & 6 & & \\
\hline \multicolumn{13}{|l|}{ Psychosocial working conditions (1-5) } \\
\hline Quantitative demands (low-high) & 4967 & & 3.4 & 1.0 & 3449 & & 3.4 & 1.0 & 1518 & & 3.3 & 1.0 \\
\hline Influence (high - low) & 4972 & & 2.2 & 0.8 & 3456 & & 2.1 & 0.8 & 1516 & & 2.3 & 0.8 \\
\hline Emotional demands (low-high) & 4970 & & 3.2 & 1.2 & 3457 & & 3.2 & 1.2 & 1513 & & 3.2 & 1.2 \\
\hline Time pressure (low-high) & 4975 & & 2.6 & 0.9 & 3458 & & 2.7 & 0.8 & 1517 & & 2.6 & 0.8 \\
\hline Role conflicts (high-low) & 4945 & & 3.6 & 0.9 & 3441 & & 3.6 & 0.9 & 1504 & & 3.7 & 0.9 \\
\hline Possibilities for development (high-low) & 4972 & & 1.9 & 0.8 & 3457 & & 1.9 & 0.8 & 1515 & & 1.9 & 0.8 \\
\hline Appreciation (high-low) & 4914 & & 2.4 & 0.9 & 3409 & & 2.4 & 0.9 & 1505 & & 2.4 & 0.9 \\
\hline \multicolumn{13}{|l|}{ Chronic diseases } \\
\hline Back disease (have or have had) & 1306 & 26 & & & 949 & 27 & & & 342 & 23 & & \\
\hline No back disease & 3705 & 74 & & & 2508 & 73 & & & 1174 & 77 & & \\
\hline Cancer inclusive leukemia (have or have had) & 212 & 4 & & & 125 & 4 & & & 84 & 6 & & \\
\hline No cancer inclusive leukemia & 4799 & 96 & & & 3332 & 96 & & & 1432 & 94 & & \\
\hline Hypertension (have or have had) & 1198 & 24 & & & 910 & 26 & & & 288 & 19 & & \\
\hline No hypertension & 3775 & 76 & & & 2545 & 74 & & & 1230 & 81 & & \\
\hline Myocardial infarction or angina pectoris (have or had) & 103 & 2 & & & 87 & 3 & & & 16 & 1 & & \\
\hline No myocardial infarction or angina pectoris & 4896 & 98 & & & 3370 & 97 & & & 1499 & 99 & & \\
\hline Stroke (have or had) & 71 & 1 & & & 55 & 2 & & & 16 & 1 & & \\
\hline No stroke & 4908 & 99 & & & 3405 & 98 & & & 1503 & 99 & & \\
\hline Chronic depression or anxiety (have or had) & 516 & 10 & & & 282 & 8 & & & 217 & 14 & & \\
\hline No chronic depression or anxiety & 4497 & 90 & & & 3173 & 92 & & & 1303 & 86 & & \\
\hline
\end{tabular}

and 60 participants (1.2\%) due to death. Average time to follow-up (ie, time to event or censoring) for the analyses with disability pension and LTSA as outcome was 4.62 (SD 0.96) and 4.62 (SD 0.95) years, respectively. A significantly higher proportion of the women had an episode of LTSA in the follow-up period compared to the men $(\mathrm{P}<0.0001)$, whereas no statistical difference, was observed for disability pension $(\mathrm{P}=0.46)$. In regard to LTSA, 367 events $(23.9 \%)$ were observed among the women and 603 events among the men (17.2\%). In regard to disability pension, 29 events $(1.9 \%)$ were observed among the women and 56 events among the men $(1.6 \%)$.

\section{Physical capability}

Table 2 shows the mean level and SD of physical capability for each of the nine tests stratified by gender. Table 3 shows the result of the association of the nine measures of physical capability with risk of disability pension and LTSA. Low capability, ie, capability that was $\geq 1$ SD below the mean, was associated with increased risk of disability pension in the fully adjusted model in eight tests: jump performance, chair-rise performance, grip strength, explosive muscle force, back strength, abdominal strength, aerobic fitness, and lung capacity.

Low capability was associated with increased risk of LTSA in the fully adjusted model in six tests: jump performance, grip strength, back strength, abdominal strength, postural balance, and lung capacity.

High capability, ie, capability that was $\geq 1$ SD above the mean, was only associated with increased risk of LTSA in the fully adjusted model for the lung capacity test. High physical capability was not associated with disability pension or LTSA in any of the remaining eight tests.

The interaction for gender in the association between each physical capability test and LTSA yielded the following results: grip strength $(\mathrm{P}=0.23)$, jump height ( $\mathrm{P}=0.28)$, aerobic fitness $(\mathrm{P}=0.29)$, back muscle strength $(\mathrm{P}=0.39)$, abdominal muscle strength $(\mathrm{P}=0.60)$, chairrise $(\mathrm{P}=0.35)$, explosive muscle force $(\mathrm{P}=0.043)$, postural balance $(\mathrm{P}=0.46)$, lung capacity $(\mathrm{P}=0.15)$ (results not shown in tables). 
Table 2. Physical capability of the nine objective measures among women and men. [SD=standard deviation; $\mathrm{FVC}_{1}$ =forced expiratory volume in one second.]

\begin{tabular}{lrrrrrrrr}
\hline \multirow{2}{*}{ Physical test } & \multicolumn{3}{c}{ Women } & & \multicolumn{4}{c}{ Men } \\
\cline { 2 - 3 } \cline { 8 - 9 } & $\mathrm{N}$ & Mean & SD & & $\mathrm{N}$ & Mean & SD \\
\hline Jump height (cm) & 1326 & 14.8 & 4.0 & 3108 & 22.0 & 4.9 \\
Chair-rise (number in 30 sec) & 1455 & 21.6 & 5.5 & 3136 & 22.3 & 5.5 \\
Grip strength (kg) & 1528 & 31.7 & 5.2 & 3501 & 50.0 & 8.3 \\
Explosive muscle force (kg/s) & 1528 & 220.6 & 50.7 & 3501 & 348.5 & 77.0 \\
Back muscle strength (kg) & 1349 & 41.4 & 11.3 & 2868 & 66.2 & 16.4 \\
Abdominal muscle strength (kg) & 1359 & 42.9 & 10.1 & 2898 & 67.7 & 13.3 \\
Postural balance (mm²) & 1509 & 810 & 775 & 3393 & 1136 & 1489 \\
Aerobic fitness (mIO2/kg/min) & 733 & 33.0 & 8.1 & 580 & 34.6 & 9.0 \\
Lung capacity (\% predicted FVC & 1530 & 94.1 & 13.5 & 3496 & 93.6 & 14.6 \\
\hline
\end{tabular}

\section{Physical capability composite score}

Table 4 and figure 1 shows the association of the number of physical tests with low capability with risk of disability pension and LTSA. In the fully adjusted model, low capability in 3-4 tests and $\geq 5$ tests were associated with increased risk of disability pension and LTSA when compared with respondents with no results reflecting low physical capability. Highly statistically significant capability-response associations were observed between the number of physical tests with low capability (continuous variable) and disability pension $(\mathrm{P}<0.0001)$ and LTSA $(\mathrm{P}<0.0001)$ (results not shown in tables).

\section{Population attributable risks}

All population attributable risks (PAR) were estimated using the estimates from the fully adjusted model 2 depicted in table 4. The PAR analysis indicates that $42 \%$ of the disability pension cases were attributable to low physical capability whereas $12 \%$ of the LTSA cases were attributable to low physical capability (results not shown in tables).

\section{Discussion}

Overall, low physical capability (ie, $\geq 1$ SD below mean for each gender) was associated with increased risk of disability pension and LTSA, whereas high physical capability (ie, $\geq 1$ SD above mean for each gender) was not associated with these health-related outcomes. A capability-response association was observed between the number of physical tests with low capability and disability pension and LTSA. PAR analyses indicate that $42 \%$ of the disability pension cases were attributable to low physical capability whereas this was the case for $12 \%$ of the LTSA cases.

\section{Strengths and weaknesses of the study}

Determining physical capability by nine different objective measures in a large heterogeneous sample of older workers is a strength of the study. Obtaining objective measures of physical capability is more challenging than using questionnaires alone, but the measurements are more precise. As an example, there is only a weakto-moderate correlation between self-reported muscle strength and objectively measured muscle strength $(\mathrm{r}=0.30-0.51$, ie, explained the variation of $9-26 \%)$ $(43,44)$. In addition, reporting bias was reduced where individuals answering questions about their own physical capabilities may be related to other variables (eg, mental health) that may affect the risk of disability pension and sickness absence.

Another strength of the study is the use of objective (ie, register-based) data on disability pension and LTSA. The DREAM register has high validity as it contains weekly information on all social transfer payments for all Danish residents (30). Even though the participants were active at the labor market and the analyses were controlled for several known chronic diseases, the observed associations between low physical capability and labor market outcome may to some extent be caused by an undiagnosed underlying disease. Due to Danish law, the DREAM register holds no information on diagnoses for LTSA and disability pension and the issue of reverse causality could, therefore, be a limitation to the present study. Thus, unmeasured confounding may have been a problem even though an extensive amount of variables were included in the final and fully adjusted model. A sensitivity analysis was, therefore, performed by additionally adjusting the final model 2 for self-rated health (not shown in the tables). Self-rated health has previously been used to capture perceived health and is a major independent predictor of objective health, morbidity, and mortality (45). The sensitivity analysis did not change the overall results, and only changed the hazard ratio estimates for the 9 different tests slightly (0.001-0.003 points). This was somewhat expected since the fully adjusted model was already adjusted for previous LTSA and several diseases (ie, back disease, cancer including leukemia, chronic anxiety or depression, stroke, hypertension, myocardial infarction, and angina pectoris). However, it can't be ruled out that low physical capability in the present study may in some cases be an indicator of yet undiagnosed disease that per se may cause LTSA and disability pension. Because sickness absence may be on the causal pathway from low physical capability (exposure) to disability pension (outcome) it could be argued that controlling for previous LTSA (model 2) in the analysis with disability pension as endpoint is an over-adjustment. However, the fully adjusted model 2 will form the base for both 
Table 3. The association of the nine measures of physical capability with risk of disability pension and long-term sickness absence (LTSA). [HR=hazard ratio; $95 \% \mathrm{Cl}=95 \%$ confidence intervals]. Significant associations in the fully adjusted model 2 are marked in bold $(\mathrm{P}<0.05)$.

\begin{tabular}{|c|c|c|c|c|c|c|c|c|c|c|c|}
\hline \multirow[t]{3}{*}{ Physical test } & \multirow[t]{3}{*}{ Capability } & \multirow[t]{3}{*}{$\mathrm{N}$} & \multirow[t]{3}{*}{$\%$} & \multicolumn{4}{|c|}{ Disability pension } & \multicolumn{4}{|c|}{ LTSA } \\
\hline & & & & \multicolumn{2}{|c|}{ Model $1^{\mathrm{a}}$} & \multicolumn{2}{|c|}{ Model $2^{b}$} & \multicolumn{2}{|c|}{ Model $1^{\mathrm{a}}$} & \multicolumn{2}{|c|}{ Model $2^{b}$} \\
\hline & & & & $\mathrm{HR}$ & $95 \% \mathrm{Cl}$ & $\mathrm{HR}$ & $95 \% \mathrm{Cl}$ & $\mathrm{HR}$ & $95 \% \mathrm{Cl}$ & HR & $95 \% \mathrm{Cl}$ \\
\hline \multirow[t]{3}{*}{ Jump height } & Mean & 3096 & 69.8 & 1 & & 1 & & 1 & & 1 & \\
\hline & High & 656 & 14.8 & 0.73 & $0.25-2.10$ & 1.28 & $0.42-3.91$ & 0.71 & $0.56-0.89$ & 0.79 & $0.62-1.01$ \\
\hline & Low & 682 & 15.4 & 4.63 & $2.62-8.17$ & 2.66 & $1.37-5.18$ & 1.69 & $1.41-2.02$ & 1.33 & $1.09-1.63$ \\
\hline \multirow[t]{3}{*}{ Chair-rise } & Mean & 3063 & 66.7 & 1 & & 1 & & 1 & & 1 & \\
\hline & High & 768 & 16.7 & 0.42 & $0.15-1.19$ & 0.29 & $0.07-1.22$ & 0.83 & $0.68-1.01$ & 0.94 & $0.76-1.16$ \\
\hline & Low & 760 & 16.6 & 4.33 & $2.71-6.91$ & 2.24 & $1.32-3.79$ & 1.39 & $1.18-1.65$ & 1.08 & $0.90-1.30$ \\
\hline \multirow[t]{3}{*}{ Grip strength } & Mean & 3517 & 69.9 & 1 & & 1 & & 1 & & 1 & \\
\hline & High & 756 & 15.0 & 0.87 & $0.43-1.79$ & 1.03 & $0.47-2.24$ & 0.93 & $0.77-1.12$ & 0.88 & $0.72-1.08$ \\
\hline & Low & 756 & 15.0 & 2.82 & $1.76-4.50$ & 2.00 & $1.19-3.35$ & 1.34 & $1.14-1.59$ & 1.21 & $1.01-1.44$ \\
\hline Explosive muscle & Mean & 3500 & 69.6 & 1 & & 1 & & 1 & & 1 & \\
\hline \multirow[t]{2}{*}{ force } & High & 767 & 15.3 & 0.61 & $0.28-1.35$ & 0.57 & $0.22-1.47$ & 0.91 & $0.75-109$ & 0.91 & $0.75-1.10$ \\
\hline & Low & 762 & 15.2 & 2.40 & $1.49-3.87$ & 1.88 & $1.13-3.13$ & 1.15 & $0.97-136$ & 1.04 & $0.87-1.25$ \\
\hline \multirow[t]{3}{*}{ Back strength } & Mean & 2914 & 69.1 & 1 & & 1 & & 1 & & 1 & \\
\hline & High & 654 & 15.5 & 0.95 & $0.42-214$ & 0.75 & $0.28-1.97$ & 1.08 & $0.89-1.31$ & 1.01 & $0.82-1.24$ \\
\hline & Low & 649 & 15.4 & 3.80 & $2.26-639$ & 2.81 & $1.59-4.98$ & 1.44 & $1.20-1.74$ & 1.32 & $1.08-1.61$ \\
\hline \multirow[t]{3}{*}{ Abdominal strength } & Mean & 2976 & 69.9 & 1 & & 1 & & 1 & & 1 & \\
\hline & High & 660 & 15.5 & 0.86 & $0.38-1.94$ & 0.65 & $0.26-1.62$ & 1.19 & $0.98-1.45$ & 0.94 & $0.76-1.16$ \\
\hline & Low & 621 & 14.6 & 3.43 & $2.04-5.76$ & 3.39 & $1.88-6.09$ & 1.51 & $1.25-1.82$ & 1.47 & $1.19-1.80$ \\
\hline \multirow[t]{3}{*}{ Postural balance } & Mean & 3854 & 78.6 & 1 & & 1 & & 1 & & 1 & \\
\hline & High & 512 & 10.4 & 0.38 & $0.12-1.21$ & 0.60 & $0.17-1.82$ & 0.85 & $0.68-1.07$ & 1.02 & $0.81-1.28$ \\
\hline & Low & 536 & 10.9 & 2.05 & $1.13-3.70$ & 1.52 & $0.77-3.00$ & 1.42 & $1.16-1.73$ & 1.30 & $1.05-1.60$ \\
\hline \multirow[t]{3}{*}{ Aerobic fitness } & Mean & 913 & 69.5 & 1 & & 1 & & 1 & & 1 & \\
\hline & High & 196 & 14.9 & 1.26 & $0.35-4.52$ & 1.32 & $0.30-5.74$ & 1.04 & $0.75-1.44$ & 0.98 & $0.68-1.41$ \\
\hline & Low & 204 & 15.5 & 4.23 & $1.80-9.98$ & 6.24 & 2.16-18.02 & 1.12 & $0.81-1.55$ & 1.13 & $0.78-1.63$ \\
\hline \multirow[t]{3}{*}{ Lung capacity } & Mean & 3568 & 71.0 & 1 & & 1 & & 1 & & 1 & \\
\hline & High & 741 & 14.7 & 0.37 & $0.13-1.01$ & 0.39 & $0.12-1.25$ & 0.77 & $0.63-0.94$ & 0.80 & $0.65-0.99$ \\
\hline & Low & 717 & 14.3 & 2.85 & $1.81-4.49$ & 2.09 & $1.26-3.46$ & 1.60 & $1.36-1.88$ & 1.30 & $1.09-1.55$ \\
\hline
\end{tabular}

${ }^{a}$ Adjusted for age and gender.

${ }^{\mathrm{b}}$ Model 1 + education, lifestyle (body mass index, smoking), chronic diseases, physical and psychosocial work environment, previous LTSA.

Table 4. The association of the number of physical tests with low capability with risk of disability pension and long-term sickness absence (LTSA). [HR=hazard ratio; $95 \% \mathrm{Cl}=95 \%$ confidence intervals]. Significant associations in the fully adjusted model 2 are marked in bold $(P<0.05)$.

\begin{tabular}{|c|c|c|c|c|c|c|c|c|c|}
\hline \multirow[t]{3}{*}{ Sum } & \multirow[t]{3}{*}{$\mathrm{N}$} & \multicolumn{4}{|c|}{ Disability pension } & \multicolumn{4}{|c|}{ LTSA } \\
\hline & & \multicolumn{2}{|c|}{ Model $1^{\text {a }}$} & \multicolumn{2}{|c|}{ Model $2^{b}$} & \multicolumn{2}{|c|}{ Model $1^{a}$} & \multicolumn{2}{|c|}{ Model $2^{b}$} \\
\hline & & $\mathrm{HR}$ & $95 \% \mathrm{Cl}$ & $\mathrm{HR}$ & $95 \% \mathrm{Cl}$ & $\mathrm{HR}$ & $95 \% \mathrm{Cl}$ & $\mathrm{HR}$ & $95 \% \mathrm{Cl}$ \\
\hline 0 & 2135 & 1 & & 1 & & 1 & & 1 & \\
\hline $1-2$ & 2244 & 1.58 & $0.85-2.90$ & 1.55 & $0.80-3.01$ & 1.21 & $1.05-1.39$ & 1.20 & $1.03-1.39$ \\
\hline $3-4$ & 539 & 5.15 & $2.75-9.68$ & 3.16 & $1.56-6.43$ & 1.74 & $1.44-2.10$ & 1.39 & $1.14-1.70$ \\
\hline$\geq 5$ & 165 & 18.21 & $9.40-35.26$ & 8.52 & $3.98-18.25$ & 2.14 & $1.56-2.93$ & 1.42 & $1.01-2.01$ \\
\hline
\end{tabular}

${ }^{\mathrm{a}}$ Adjusted for age and gender.

${ }^{\mathrm{b}}$ Model 1 + education, lifestyle (body mass index, smoking), chronic diseases, physical and psychosocial work environment, previous LTSA.

health-related outcomes for the discussion, in spite of the possible bias associated with over-adjustment in the analyses with disability pension as outcome.

A weakness of the study is the low response rate to the CAMB survey which could have introduced selection bias. Previous findings from the CAMB study found that respondents who filled in the questionnaire $(31 \%$ of the invited 17937 persons) and non-responders were comparable in regard to educational level and general health, whereas a larger proportion of respondents were employed (22). Further, Møller et al (37) showed that participants attending the physical examination (ie, the study sample for the present study) had significantly higher education, were more likely to be employed, whereas no statistically significant difference existed in use of the health care system compared to the nonresponders/non-participants.

A weakness of the study is that psychosocial work environment was retrospectively evaluated to cover the whole working life and could, therefore, be prone to potential bias, in particular, recall bias. Asking participants to combine exposures during their working life in a single number for their average level of quantitative demands, decision authority, emotional demands, time pressure, role conflicts, possibilities for development, and appreciation is a very limited step towards a life course perspective (46). Hence, it is not possible to evaluate the influence of current psychosocial work environment (ie, at the point 


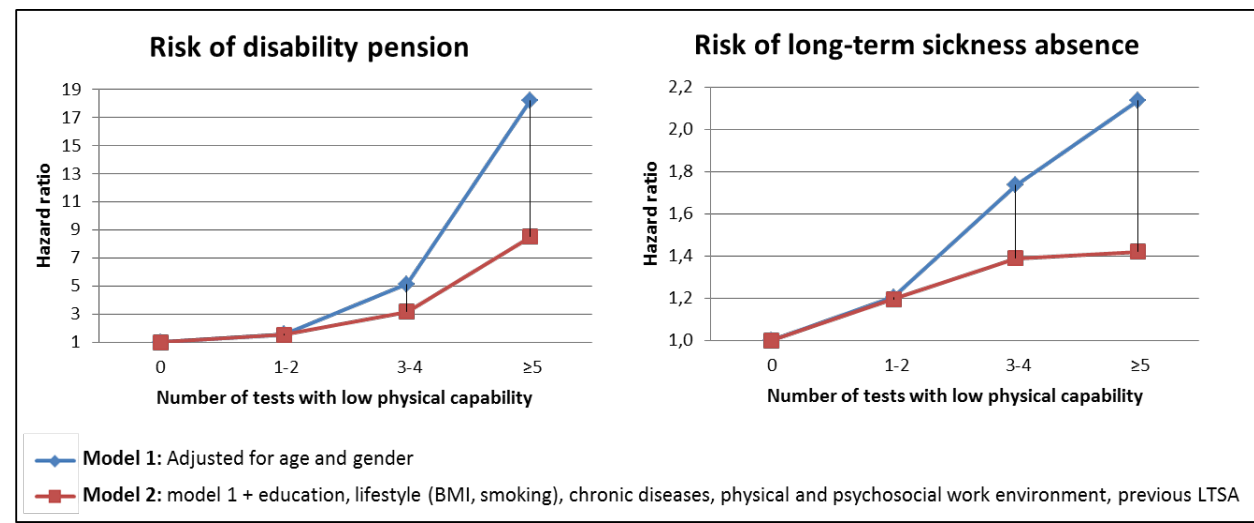

Figure 1. The association of the number of physical tests with low capability with risk of disability pension (left) and long-term sickness absence (right).

of data collection) on the association between physical capability and health-related labor market outcomes. In addition, cognitive ability (not related to psychosocial work environment) may influence the association between physical capability and health-related outcomes $(16,47)$. Thus, we controlled the analyses for educational attainment to provide a proxy for cognitive ability (cognitive ability in youth likely determines educational attainment). Unfortunately, we did not have a measure to cover agerelated changes in cognitive ability which theoretically could have influenced the present results.

The low number of cases for disability pension is an important weakness to the study and could have introduced insufficient statistical power, thus increasing the risk of non-significant findings. Thus, wide confidence intervals for the risk estimates were observed in the analyses with disability pension as outcome measure (see table 3 and 4). Importantly, new reforms have made it more difficult to be granted a disability pension in Denmark and the average age to obtain a disability pension has increased from 45.8 years in 2011 to 48.1 years in 2015. Hence, there is a tendency for municipalities in Denmark to recognize fewer disability pensions after the introduction of the new reforms in 2012. However, highly statistically significant associations were still found between low capability and disability pension, indicating the existence of a true association. Nevertheless, this degree of uncertainty in regard to the risk estimates in the analyses with disability pension as outcome could still have influenced the overall results and may explain some of the observed difference in risk estimate-size and PAR between the analyses with disability pension and LTSA as outcome measures.

\section{Interpretation of results}

The study showed that low capability in the nine objective physical measures was associated with an increased risk of permanently or temporarily leaving the workforce due to poor health (ie, disability pension and LTSA, respectively). Previous studies employing both self-rated and objectively measured physical capability have observed an association between low physical capability and poor health. Rice et al (13) found that older workers from the English Longitudinal Study of Ageing with impaired self-rated physical mobility (ie, difficulty walking a quarter mile) were at increased risk of early work exit. Further, in a cross-sectional design, Borch-Supan et al (14) observed a significant deterioration of self-assessed health among older participants from the SHARE study who just started to receive disability benefits. However, this deterioration was much less pronounced when health was obtained more objectively by hand-grip strength, which indicates justification bias in self-assessed health (14). This is in agreement with Kalwij et al (15) emphasizing the need for objective health indicators when analyzing the relationship between health status and labor force participation. A study employing objectively measured physical capability showed that aerobic fitness (ergometer bicycle test) and handgrip muscle strength in late adolescence were independently and jointly associated with longterm risk of poor health such as vascular disease and arrhythmia (48). Additionally, Stafford et al (16) found that better physical capability (objectively measured by grip strength, chair-rise time, and one-legged balance test) was associated with greater likelihood of participating in bridge or voluntary employment after retirement from main occupation (self-reported). However, they found no association with performance-based physical capability score and retiring for negative reasons (ie, own health, partner's health, becoming a carer, bereavement, made redundant, unhappy with job or with working, work problems) (16). The present study elaborates on these previous findings by showing that low objectively measured physical capability increases 
the risk for register-based disability pension and LTSA, whereas high capability was not associated with these health-related outcomes. Specifically, low jump performance, low abdominal muscle strength, low back muscle strength, and low aerobic fitness showed the highest risks estimates of disability pension.

To assess the combined effect of low capability in multiple tests, a physical capability composite score was created. The analyses showed a capability-response relationship between the number of physical tests with low capability and disability pension and LTSA ie, increased risk from exposure to a higher number of physical tests with low capability (table 4 and figure 1). Even though the time for physical capability assessment is limited in research and clinical settings, our results indicate a value of conducting a range of different capability tests $(8,16)$.

In general, we observed higher risk estimates in the analyses with disability pension as endpoint compared to LTSA. This was also reflected in the PAR analyses showing that $42 \%$ of the disability pension cases were attributable to low physical capability whereas this was the case for $12 \%$ of the LTSA cases. Both LTSA and disability pension reflects a complex interaction of health and work characteristics and can be a consequence of the scenario where requirements at work exceed individual resources. Even though both LTSA and disability pension is considered health-related labor market outcomes, differences may still exist that could assist the interpretation of the present results. Poor health is an established risk factor for leaving the labor market and disability pension seems to be preceded by sickness absence. However, sickness absence could to a larger extent be entitled to other causes than poor health such as social factors. Hence, health-related factors, such as physical capability, may influence the transition into disability pension (permanently unable to work due to ill health) and LTSA (temporarily unable to work due to ill health) differently. In line with this, a proportion of workers on LTSA will later return to work whereas disability pension is a social benefit for people with a significant and permanent loss of work ability (ie, with more severe and long lasting health problems). It should also be mentioned that the low number of cases and the accompanied wide $\mathrm{CI}$ could have introduced a degree of uncertainty in regard to the accuracy of the risk estimates in the analyses with disability pension as outcome.

The results show that low physical capability is associated with increased risk of LTSA and disability pension irrespectively of level of physical activity level at work. Hence, low physical capability may lead to an imbalance between individual capacity and work demands thereby challenging health and labor market participation among both workers engaged in physical and sedentary job tasks. In the present study sample, $53 \%$ reported sedentary job tasks, whereas the remaining reported moderate, hard or very hard physical work (see table 1). A previous study on the CAMB population showed that physical work during working life increased the risk of both LTSA and disability pension when compared to sedentary work (31). Even though physical work demands will likely show a small decrease in many industries (6-8), low physical capability may especially make it difficult for employees engaged in hard physical work to cope with the physical demands at work by challenging the physical reserve capacity (ie, the difference between physical work demands and physical capacity of the worker). Overall, the present study suggests that promoting physical capability among older workers with low capability may contribute to extend working lives. The PAR analyses indicated that $>40 \%$ of all cases of disability pension in this study were attributable to low physical capability. Hence, a large proportion of disability pensions could theoretically be reduced by increasing physical capability in midlife or earlier. This could, for example, be achieved by promoting physical activity in the workplace, such as strength training. Previous research has shown that strength training in the elderly can increase muscle mass, strength, and functional performance (49). In addition, strength training at the workplace for 10-12 weeks has been shown effective for increasing physical capability in middle-aged workers, including grip strength, back strength and jump performance $(50,51)$. However, knowledge is lacking in physical activity interventions at the workplace specifically targeting older workers. Future longitudinal studies should investigate the effect of physical activity at the workplace for retaining older workers in the labor market.

\section{Concluding remarks}

Low physical capability was associated with increased risk of disability pension and LTSA whereas high capability was not associated with these health-related outcomes. Importantly, a capability-response association was observed between the number of physical tests with low capability and disability pension and LTSA. The results indicated that $42 \%$ of the disability pension cases were attributable to low physical capability whereas this was the case for $12 \%$ of the LTSA cases. Promoting physical capability among older workers with low capability may contribute to prolonged working careers.

\section{Ethical approval}

The Danish Data Protection Agency approved this study (j.nr. 2015-41-4232). The local ethical committee and the Danish Data Protection Agency have previously approved the CAMB as a database combining three cohorts: approval No. H-A-2008-126 and No. 201341-1814, respectively (22). Participants were informed 
about the content and purpose of the CAMB study and gave their written informed consent to participate (22).

\section{Availability of data and materials}

The dataset that supports the findings of this study are available from the CAMB steering committee but restrictions apply to the availability of these data, which were used under license for the current study and so are not publicly available. Data are however available from the authors upon reasonable request and with permission of the CAMB steering committee.

\section{Competing interests}

None declared.

\section{Funding}

This study was supported by a grant from the Danish Working Environment Research Fund (Grant no. 20130068772/3).

\section{Acknowledgments}

The Copenhagen Aging and Midlife Biobank has been supported by a generous grant from the VELUX FOUNDATION (VELUX26145 and 31539). The authors thank the staff at Department of Public Health and National Research Centre for the Working Environment, who undertook the data collection. Further thanks to Kirsten Avlund $\dagger$, Helle Bruunsgaard, Nils-Erik Fiehn, Poul Holm-Pedersen, Rikke Lund and Merete Osler, who initiated and established the Copenhagen Aging and Midlife Biobank from 2009-2011. The authors acknowledge the crucial role of the initiators and steering groups of The Metropolit Cohort, The Copenhagen Perinatal Cohort and The Danish Longitudinal Study on Work, Unemployment and Health.

\section{References}

1. Boss GR, Seegmiller JE. Age-related physiological changes and their clinical significance. West J Med 1981 Dec;135(6):434-40.

2. Newton RU, Hakkinen K, Hakkinen A, McCormick M, Volek J, Kraemer WJ. Mixed-methods resistance training increases power and strength of young and older men. Med Sci Sports Exerc 2002 Aug;34(8):1367-75. https://doi. org/10.1097/00005768-200208000-00020.

3. Singh-Manoux A, Kivimaki M, Glymour MM, Elbaz A,
Berr C, Ebmeier KP et al. Timing of onset of cognitive decline: results from Whitehall II prospective cohort study. BMJ 2012 Jan;344:d7622. https://doi.org/10.1136/bmj. d7622.

4. Reeuwijk KG, van Klaveren D, van Rijn RM, Burdorf A, Robroek SJ. The influence of poor health on competing exit routes from paid employment among older workers in 11 European countries. Scand J Work Environ Health 2017 Jan;43(1):24-33. https://doi.org/10.5271/sjweh.3601.

5. EU-OSHA. Discussion paper: A review on the future of work: Robotics. European Agency for Safety and Health at Work; 2017.

6. Torgén M, Kilbom A. Physical work load between 1970 and 1993--did it change? Scand J Work Environ Health 2000 Apr;26(2):161-8. https://doi.org/10.5271/sjweh.526.

7. de Zwart BC, Frings-Dresen MH, van Dijk FJ. Physical workload and the aging worker: a review of the literature. Int Arch Occup Environ Health 1995;68(1):1-12. https://doi. org/10.1007/BF01831627.

8. Cooper R, Strand BH, Hardy R, Patel KV, Kuh D. Physical capability in mid-life and survival over 13 years of followup: british birth cohort study. BMJ 2014 Apr;348:g2219. https://doi.org/10.1136/bmj.g2219.

9. Rosero-Bixby L, Dow WH. Predicting mortality with biomarkers: a population-based prospective cohort study for elderly Costa Ricans. Popul Health Metr 2012 Jun;10(1):11. https://doi.org/10.1186/1478-7954-10-11.

10. Studenski S, Perera S, Patel K, Rosano C, Faulkner K, Inzitari $\mathrm{M}$ et al. Gait speed and survival in older adults. JAMA 2011 Jan;305(1):50-8. https://doi.org/10.1001/ jama.2010.1923.

11. Hansen ÅM, Andersen LL, Skotte J, Christensen U, Mortensen OS, Molbo D et al. Social class differences in physical functions in middle-aged men and women. J Aging Health 2014 Feb;26(1):88-105. https://doi. org/10.1177/0898264313508188.

12. Gardener EA, Huppert FA, Guralnik JM, Melzer D. Middleaged and mobility-limited: prevalence of disability and symptom attributions in a national survey. J Gen Intern Med 2006 Oct;21(10):1091-6. https://doi.org/10.1111/j.15251497.2006.00564.x.

13. Rice NE, Lang IA, Henley W, Melzer D. Common health predictors of early retirement: findings from the English Longitudinal Study of Ageing. Age Ageing 2011 Jan;40(1):54-61. https://doi.org/10.1093/ageing/afq153.

14. Börsch-Supan A, Brugiavini A, Croda E. The Role of Institutions and Health in European Patterns of Work and Retirement. J Eur Soc Policy 2009 Oct;19(4):341-58. https://doi.org/10.1177/1350506809341515.

15. Kalwij A, Vermeulen F. Health and labor force participation of older people in Europe: what do objective health indicators add to the analysis? Health Econ 2008 May;17(5):619-38. https://doi.org/10.1002/hec.1285.

16. Stafford M, Cooper R, Cadar D, Carr E, Murray E, Richards $\mathrm{M}$ et al. Physical and cognitive capability in mid-adulthood 
as determinants of retirement and extended working life in a British cohort study. Scand J Work Environ Health 2017 Jan;43(1):15-23. https://doi.org/10.5271/sjweh.3589.

17. von Elm E, Altman DG, Egger M, Pocock SJ, Gøtzsche PC, Vandenbroucke JP; STROBE Initiative. Strengthening the Reporting of Observational Studies in Epidemiology (STROBE) statement: guidelines for reporting observational studies. BMJ 2007 Oct;335(7624):806-8. https://doi. org/10.1136/bmj.39335.541782.AD.

18. Sundstrup E, Hansen ÅM, Mortensen EL, Poulsen OM, Clausen T, Rugulies R et al. Influence of physical and psychosocial work environment throughout life and physical and cognitive capacity in midlife on labor market attachment among older workers: study protocol for a prospective cohort study. BMC Public Health 2016 Jul;16:629. https:// doi.org/10.1186/s12889-016-3290-8.

19. Osler M, Lund R, Kriegbaum M, Christensen U, Andersen AM. Cohort profile: the Metropolit 1953 Danish male birth cohort. Int J Epidemiol 2006 Jun;35(3):541-5. https://doi. org/10.1093/ije/dyi300.

20. Christensen U, Lund R, Damsgaard MT, Holstein BE, Ditlevsen S, Diderichsen F et al. Cynical hostility, socioeconomic position, health behaviors, and symptom load: a cross-sectional analysis in a Danish population-based study. Psychosom Med 2004 Jul-Aug;66(4):572-7. https:// doi.org/10.1097/01.psy.0000126206.35683.d1.

21. Zachau-Christiansen B. Development during the first year of life. Helsingør, Denmark: Poul AndersensForlag; 1972.

22. Avlund K, Osler M, Mortensen EL, Christensen U, Bruunsgaard H, Holm-Pedersen $\mathrm{P}$ et al. Copenhagen Aging and Midlife Biobank (CAMB): an introduction. J Aging Health 2014 Feb;26(1):5-20. https://doi. org/10.1177/0898264313509277.

23. Jørgensen MB, Ektor-Andersen J, Sjøgaard G, Holtermann A, Søgaard K. A randomised controlled trial among cleaners-effects on strength, balance and kinesiophobia. BMC Public Health 2011 Oct;11:776. https://doi.org/10.1186/1471-2458$11-776$.

24. Jones CJ, Rikli RE, Beam WC. A 30-s chair-stand test as a measure of lower body strength in community-residing older adults. Res Q Exerc Sport 1999 Jun;70(2):113-9. https://doi.org/10.1080/02701367.1999.10608028.

25. Møller A, Reventlow S, Hansen ÅM, Andersen LL, Siersma V, Lund $\mathrm{R}$ et al. Does physical exposure throughout working life influence chair-rise performance in midlife? A retrospective cohort study of associations between work and physical function in Denmark. BMJ Open 2015 Nov;5(11):e009873. https://doi.org/10.1136/ bmjopen-2015-009873.

26. Jakobsen MD, Sundstrup E, Randers MB, Kjær M, Andersen LL, Krustrup P et al. The effect of strength training, recreational soccer and running exercise on stretch-shortening cycle muscle performance during countermovement jumping. Human Movement Science [Internet]. 2012 Mar 5 [cited 2012 Mar 21]; Available from: http://www.ncbi.nlm.nih. gov//22397814
27. Astrand PO, Ryhming I. A nomogram for calculation of aerobic capacity (physical fitness) from pulse rate during sub-maximal work. J Appl Physiol 1954 Sep;7(2):218-21. https://doi.org/10.1152/jappl.1954.7.2.218.

28. Miller MR, Hankinson J, Brusasco V, Burgos F, Casaburi R, Coates A et al.; ATS/ERS Task Force. Standardisation of spirometry. Eur Respir J 2005 Aug;26(2):319-38. https:// doi.org/10.1183/09031936.05.00034805.

29. Burr H, Pedersen J, Hansen JV. Work environment as predictor of long-term sickness absence: linkage of selfreported DWECS data with the DREAM register. Scand J Public Health 2011 Jul;39(7 Suppl):147-52. https://doi. org/10.1177/1403494811401480.

30. Hjollund NH, Larsen FB, Andersen JH. Register-based followup of social benefits and other transfer payments: accuracy and degree of completeness in a Danish interdepartmental administrative database compared with a population-based survey. Scand J Public Health 2007;35(5):497-502. https:// doi.org/10.1080/14034940701271882.

31. Sundstrup E, Hansen ÅM, Mortensen EL, Poulsen OM, Clausen T, Rugulies R et al. Retrospectively assessed physical work environment during working life and risk of sickness absence and labor market exit among older workers. Occup Environ Med 2018 Feb;75(2):114-123. https://doi.org/10.1136/oemed-2016-104279.

32. Sundstrup E, Hansen ÅM, Mortensen EL, Poulsen OM, Clausen T, Rugulies R et al. Cumulative occupational mechanical exposures during working life and risk of sickness absence and disability pension: prospective cohort study. Scand J Work Environ Health 2017 Sep;43(5):41525. https://doi.org/10.5271/sjweh.3663.

33. Kuh D, Bassey EJ, Butterworth S, Hardy R, Wadsworth ME; Musculoskeletal Study Team. Grip strength, postural control, and functional leg power in a representative cohort of British men and women: associations with physical activity, health status, and socioeconomic conditions. J Gerontol A Biol Sci Med Sci 2005 Feb;60(2):224-31. https://doi.org/10.1093/gerona/60.2.224.

34. Toft-Petersen AP, Wulff J, Harrison DA, Ostermann M, Margarson M, Rowan KM et al. Exploring the impact of using measured or estimated values for height and weight on the relationship between BMI and acute hospital mortality. J Crit Care 2018 Apr;44:196-202. https://doi.org/10.1016/j. jerc.2017.11.021.

35. Carter BD, Abnet CC, Feskanich D, Freedman ND, Hartge P, Lewis CE et al. Smoking and mortality--beyond established causes. N Engl J Med 2015 Feb;372(7):631-40. https://doi.org/10.1056/NEJMsa1407211.

36. Valkeinen $\mathrm{H}$, Harald $\mathrm{K}$, Borodulin K, Mäkinen TE, Heliövaara M, Leino-Arjas $\mathrm{P}$ et al. Educational differences in estimated and measured physical fitness. Eur J Public Health 2013 Dec;23(6):998-1002. https://doi.org/10.1093/ eurpub/ckt049.

37. Møller A, Reventlow S, Hansen AM, Andersen LL, Siersma $\mathrm{V}$, Lund $\mathrm{R}$ et al. Does a history of physical exposures at work 
affect hand-grip strength in midlife? A retrospective cohort study in Denmark. Scand J Work Environ Health 2013 Nov;39(6):599-608. https://doi.org/10.5271/sjweh.3368.

38. Pejtersen JH, Kristensen TS, Borg V, Bjorner JB. The second version of the Copenhagen Psychosocial Questionnaire. Scand J Public Health 2010 Feb;38(3 Suppl):8-24. https:// doi.org/10.1177/1403494809349858.

39. Sundstrup E, Jakobsen MD, Mortensen OS, Andersen LL. Joint association of multimorbidity and work ability with risk of long-term sickness absence: a prospective cohort study with register follow-up. Scand J Work Environ Health 2017 Mar;43(2):146-54. https://doi.org/10.5271/ sjweh.3620.

40. Knudsen AK, Øverland S, Aakvaag HF, Harvey SB, Hotopf M, Mykletun A. Common mental disorders and disability pension award: seven year follow-up of the HUSK study. J Psychosom Res 2010 Jul;69(1):59-67. https://doi. org/10.1016/j.jpsychores.2010.03.007.

41. Virtanen M, Ervasti J, Mittendorfer-Rutz E, Lallukka T, Kjeldgård L, Friberg E, et al. Work disability before and after a major cardiovascular event: a ten-year study using nationwide medical and insurance registers. Sci Rep . 2017 25;7(1):1142.

42. Andersen LL, Fallentin N, Thorsen SV, Holtermann A. Physical workload and risk of long-term sickness absence in the general working population and among blue-collar workers: prospective cohort study with register follow-up. Occup Environ Med 2016 Apr;73(4):246-53. https://doi. org/10.1136/oemed-2015-103314.

43. Strøyer J, Essendrop M, Jensen LD, Warming S, Avlund K, Schibye B. Validity and reliability of self-assessed physical fitness using visual analogue scales. Percept Mot Skills 2007 Apr;104(2):519-33. https://doi.org/10.2466/pms.104.2.519533.

44. Haskell WL. Physical activity by self-report: a brief history and future issues. J Phys Act Health 2012 Jan;9 Suppl 1:S5-10. https://doi.org/10.1123/jpah.9.s1.s5.
45. Idler EL, Benyamini Y. Self-rated health and mortality: a review of twenty-seven community studies. J Health Soc Behav 1997 Mar;38(1):21-37. https://doi. org/10.2307/2955359.

46. Sundstrup E, Hansen ÅM, Mortensen EL, Poulsen OM, Clausen T, Rugulies R, et al. Retrospectively assessed psychosocial working conditions as predictors of prospectively assessed sickness absence and disability pension among older workers. BMC Public Health . 2018 17;18(1):149.

47. Kuh D, Cooper R, Hardy R, Guralnik J, Richards M; Musculoskeletal Study Team. Lifetime cognitive performance is associated with midlife physical performance in a prospective national birth cohort study. Psychosom Med 2009 Jan;71(1):38-48. https://doi.org/10.1097/ PSY.0b013e31818a1620.

48. Andersen K, Rasmussen F, Held C, Neovius M, Tynelius $\mathrm{P}$, Sundström J. Exercise capacity and muscle strength and risk of vascular disease and arrhythmia in 1.1 million young Swedish men: cohort study. BMJ 2015 Sep;351:h4543. https://doi.org/10.1136/bmj.h4543.

49. Aagaard P, Suetta C, Caserotti P, Magnusson SP, Kjaer $M$. Role of the nervous system in sarcopenia and muscle atrophy with aging: strength training as a countermeasure. Scand J Med Sci Sports 2010 Feb;20(1):49-64. https://doi. org/10.1111/j.1600-0838.2009.01084.x.

50. Sundstrup E, Jakobsen MD, Andersen CH, Jay K, Persson $\mathrm{R}$, Aagaard $\mathrm{P}$ et al. Effect of two contrasting interventions on upper limb chronic pain and disability: a randomized controlled trial. Pain Physician 2014 Mar-Apr;17(2):145-54.

51. Jay K, Jakobsen MD, Sundstrup E, Skotte JH, Jørgensen $\mathrm{MB}$, Andersen $\mathrm{CH}$ et al. Effects of kettlebell training on postural coordination and jump performance: A randomized controlled trial. Journal of strength and conditioning research / National Strength \& Conditioning Association [Internet]. 2012 Jul 26 [cited 2012 Aug 28]. Available from: http://www.ncbi. nlm.nih.gov//22843044.

Received for publication: 15 January 2019 